\title{
EXCEED - EXCELLENCE CENTER FOR DEVELOPMENT COOPERATION SUSTAINABLE WATER MANAGEMENT IN DEVELOPING COUNTRIES
}

\author{
Prof. Dr. mult. Dr. h. c. Muefit Bahadir \\ Technische Universitaet Braunschweig \\ Institute of Environmental and Sustainable Chemistry \\ Hagenring 30, D-38106 Braunschweig, Germany \\ m.bahadir@tu-bs.de / www.exceed.tu-braunschweig.de
}

\begin{abstract}
The Excellence Center for Development Cooperation Sustainable Water Management in Developing Countries, implemented by TU Braunschweig together with 23 partner universities in developing countries, is one of five projects on Millennium Development Goals MDG, which were awarded funding with one million Euro per year each over a five-year period by the German Ministry for Development Cooperation (BMZ) and the German Academic Exchange Service (DAAD).

Through its specific study programs and research profile, TU Braunschweig offers outstanding expertise in Sustainable Water Management in Developing Countries. Pioneering research and academic cooperation projects with strategic partners from developing countries in Latin America, the Middle East, and South-East Asia have been developed with a strong focus on sustainable and transferable solutions for each country's predominant water-related issues.

Based on a world-wide network of 24 partners the Excellence Center will focus on capacity building in developing countries through training of and networking between experts. The Coordinating Unit is located at the TU Braunschweig; three Satellite Centers are established at the Mut'ah University in Karak, Jordan, the Universidad de Guadalajara in Guadalajara, Mexico, and the Water Resources University in Hanoi, Vietnam.

The project partners are aiming at extending the cooperation also to the Sub-Sahara Region. This presentation given by the project chairman is going to provide an insight into the project's goals in order to discover interested colleagues from the Sub-Sahara Region and to establish an African Branch of this worldwide network for capacity building through education.
\end{abstract}

\section{KEY WORDS}

Sustainable Water Management, Developing Countries, Capacity Building, Networking, Curriculum Development

\section{INTRODUCTION}

Although $70 \%$ of earth's surface is covered with water, the freshwater reserves available for the mankind are vanishingly small. Of the 1.38 billion $\mathrm{km}^{3}$ water available on earth, $97.4 \%$ are made up of the saltwater of the oceans, and only available for anthropogenic use after immense technical and monetary efforts. Out of the remaining $2.6 \%$ of freshwater reserves $2 \%$ are stored in polar, marine, and glacial ice, and are thus not available for economic and, predominantly, for ecological reasons. This leaves $0.6 \%$ ( 0.08 billion $\left.\mathrm{km}^{3}\right)$ in form of ground and surface water, and soil and air moisture for the usage through the rapidly growing human population.

It is estimated that 1.1 billion people have no access to drinking water, and 2.6 billion do not have any sanitary facilities or wastewater disposal. Additionally, due to the urbanization and industrialization of former rural areas, the demand for water resources has grown and become increasingly polluted. Therefore, »water « is undeniably at the heart of the MDG »Environmental Protection and Sustainability «, and the sustainable use of water is an important issue for development cooperation. [1]

Through its specific study programs and research profile, TU Braunschweig offers outstanding expertise in »Sustainable Water Management in Developing Countries«. [2] Cooperation projects focus on three areas: sewage water and irrigation in arid and semi-arid regions, water management in mega-cities, and the treatment and reuse of industrial wastewater. These areas are linked with an integrated water resources management with regard to water quantity and quality aspects. [3]

Pioneering research and academic cooperation in those three areas have been established by the TU Braunschweig along with strategic partners from developing countries in Latin America, the Middle East, and South-East Asia. The focus is set on sustainable and transferable solutions for each country's predominant water-related issues. The interdisciplinary approach integrates the fields of sustainable water management, biotechnology and bioengineering, sanitary and environmental engineering, waste management, environmental chemistry, and geo-ecology. The key aspects of the program are the availability of and access to water, water usage, as well as treatment and reuse of reclaimed wastewater from ecological, economic and social point of viewpoints. 
The utilization scenarios that exist are manifold, and so are the academic disciplines, which have to cooperate to reach the MDG of Sustainable Water Management. The focus of the cooperation is on research and development, and is about avoiding the overexploitation of resources and the contamination of water reserves while using concepts tailored to the needs of the relevant regions. In order to implement these concepts and to increase the acceptance of measures taken within the respective cultural groups, socio-economic training concepts and tools also have to be created. In addition to the interdisciplinary and technological partners, it is essential to involve regional stakeholders in research projects in order to guarantee the necessary acceptance for the developed training opportunities and research results.

So far, TU Braunschweig has cooperated with its partners from developing countries in numerous projects for implementing the concept. [e.g. 4-6] Within the frame of the Exceed Project a globally acting network for development cooperation in the field of "Sustainable Water Management « will be established. [7]

Many projects in development cooperation fail for ignoring the importance of socio-cultural aspects, and solely concentrating on scientific and technical problems. The end of the active involvement of experts from industrialized countries often leads to failure in the implementation stage of a project. [8] Especially, projects related to water supply and use gain little recognition if the various political, cultural, and social meanings of water in different regions are not considered.

TU Braunschweig actively encourages the involvement and participation of local stakeholders in order to attain religious and cultural support for the projects and thereby to ensure the success of the development cooperation. Only through extensive consideration of the social reality and cultural differences of the respective countries, the ecological and economic advantages of sustainability can be reached, and the living standard in developing countries fundamentally be improved.

Three main problems can be identified within this context and have to be dealt with in all projects of development cooperation:

- Which influence does an innovation have on the new societal context? Are the people involved able and willing to adopt and accept this innovation at all? Which obstacles and kind of conductive factors must be considered for the innovation process?

- In which way are the mental, institutional and technical aspects of an innovation process interrelated? How do they influence each other?

- How can be the asymmetry problem dealt with arising from the transfer constellation (in terms of developmental gap between partners, different cultural contexts, the teacher student relation etc.)?

\section{STRUCTURE OF THE DEVELOPMENT COOPERATION}

The development cooperation of TU Braunschweig in the field of "Sustainable Water Management « comprises three areas: (i) Higher Education, (ii) Research, and (iii) Knowledge Transfer. Working together with local partners from universities, public authorities and NGOs allows helping to build the necessary knowledge and competences. The main goal is to guarantee the project's long-term success. Building self-supporting structures is the main characteristic of the over-all approach of TU Braunschweig and its partners in developing countries.

\subsection{Higher Education}

As an important step, master degree programs in Environmental Engineering at PUC Rio de Janeiro and UNAM in Mexico City have been developed jointly. The courses are also offered as intensive courses for students who are already working. The distance learning program PROWATER offered at TU Braunschweig also combines further education together with master degree studies for employed participants from developing countries. [9]

Through this strong emphasis on participants, who are already part of the local workforce, these programs are strongly practice oriented and help to build cooperation with relevant public authorities and industries while concentrating on key economic challenges. A network between universities and local companies can be built through the participants serving as a starting point for future cooperation.

Based on jointly developed programs, the next step comprises the establishment of dual degree master courses. As a visible result of close collaboration and authentic dialogue, a dual degree masters program in Environmental Chemistry has been developed starting from teaching staff exchange with Gadjah Mada University (UGM) in Yogyakarta/Indonesia, with graduate students taking courses and receiving their degrees from both universities, Yogyakarta and Braunschweig. The Pertanian Institute Bogor (IPB) in Bogor/ Indonesia, where DAAD Alumni are doing research in Sustainable Biotechnology and Oceanography, is currently being integrated into this program.

\subsection{Research}

Along with the implementation of joint study courses, the partners closely cooperate in research projects. Thus, it is not only possible to implement a transfer of knowledge between partners in developing countries, but also a transfer from North to South and vice versa. An example is the joint cooperation in Indonesia between IPB and the UGM in the areas of sustainable chemistry, biotechnology, and oceanography. A trilocal R\&D project with IPB and UGM is currently under way, the aim being to raise high-yield oil-rich green algae in fresh water ponds and marine basins and to process them into 
chemical feedstock. Aspects of marine ecology are being investigated within this network at the Institute of Oceanography of the University of Rhode Island (URI) in Narragansett/USA. TU Braunschweig is not only going to bring together and to coach these partners, but it is also investigating technology transfer related to the chemical transformation of the algae based bio-oils to lubricants and auxiliary materials, and introducing them into industrial application.

The Leichtweiss Institute for Hydraulic Engineering and Water Resources (LWI) at the TU Braunschweig is coordinating a research project to reduce water pollution through sustainable water management in the Saigon Dongnai River basin in Vietnam. Employing experiments at pilot scale and numerical modeling a new approach to an innovative and science-based water pollution control management has been formulated, which adapts to regional needs. The overall aim of the project is the development of methods to improve the water quality in surface waters in tropical and subtropical developing countries.

\subsection{Knowledge Transfer}

Knowledge transfer projects play an important role especially in the international alumni work at TU Braunschweig. Several expert workshops and summer schools are held annually for scientists from developing countries. These projects aim at improving the knowledge of the participants, which will then enhance the teaching and research at their home institutions. But a sociocultural dialogue is also supposed to be launched among scientists and regional stakeholders.

\section{QUALITY FEATURES OF THE DEVELOPMENT COOPERATION PROJECTS}

The results of the TU Braunschweig's development cooperation in sustainable water management are characterized by four qualitative criteria: (i) Transferability, (ii) Reciprocity, (iii) Networking, and (iv) Successful Implementation. All project results and measures are transferable through degree programs, research projects, and technology transfer to similar climate zones and regions. For instance, the experiences made while establishing the master degree program in Environmental Engineering at PUC Rio served to establish a similar program at UNAM in Mexico and similar structures at UGM in Indonesia.

Exceed Projects of TU Braunschweig and the Developing Countries are distinguished by reciprocity, with both parties profiting from joint activities. Jointly developed degree programs lead to a self-supporting structure for expert education being created in the respective country, whereas the TU Braunschweig can add development-related modules to its curriculum. The exchange of doctoral candidates and researchers assures excellence in the education of teaching and research staff for developing countries, and individual contacts for future cooperation of all network members. The driving force behind the development cooperation is made up of the more than 300 doctoral candidates from Developing Countries doing their research work and theses at the TU Braunschweig. As future university professors, researchers and decision makers, these groups do the developmental work in their native countries and become partners for future cooperation in research and technology transfer.

As a result of the development cooperation, links are built not only between TU Braunschweig and its partners, but also among developing countries and with other industrialized countries. Such networks comprise higher education institutions as well as research institutions, public authorities, ministries, and companies as well as NGOs. All projects are planned and implemented according to the principle »best available and best adapted«. Close cooperation with the respective partners guarantees the long-term success of such projects.

\section{RELEVANCE}

Being a research university with a focus on engineering and sciences, TU Braunschweig consequently aims at using an interdisciplinary approach alongside appropriate methods and technologies regarding the supply, usage, purification and reutilization of water. Until now, the eminence of the topic »water « becomes apparent mainly in developing countries. However, it will gain importance for the industrialized countries in the future, as well. The Exceed Project is becoming a visible sign and raise public awareness for the future importance of the topic for the mankind in developing countries, in Germany, and in other industrialized countries, as well.

TU Braunschweig's development cooperation projects in the area of »Sustainable Water Management « have led to the bundling of competences and to the emergence of a worldwide network of partners. Through collaborative efforts, the topic has been a focus in research, education, and technology transfer. The establishment of estimable study and research facilities in the field of water management has resulted in the partners in developing countries evolving into reputable centers of competence across regional and international borders.

TU Braunschweig is integrating the results of the Exceed Projects into its ongoing research as well as into its curricula, thus widening its spectrum of academic fields. With »Water Management« and »Waste Management «, the bachelor study program »Environmental Engineering « at TU Braunschweig features two modules pertaining to developing countries. A module specializing in "Environmental Protection in Developing Countries« is also planned within the framework of a master program. Relevant study programs have equally been established at partner institutions, like the master program »Water Management« at Ain Shams University in Cairo, Egypt, which presently serves as a model for other Egyptian universities. 
Projects at TU Braunschweig resulted already in introducing environmental standards in Developing Countries. For instance, a decision support system and the scientific approach to control eutrophication of the Lake Chao in the Anhui Province have been developed together with the Chinese Ministry of Science and Technology. They are now used as blueprints for the remediation of further water bodies in China. [10]

To end with, other Millennium Development Goals have been promoted alongside »Environmental Sustainability «. Improved water quality and the reuse of water give rural population and micro-firms better chances to secure their subsistence, thus preventing extreme poverty and hunger. Clean potable water also reduces infant mortality in developing countries and helps to prevent epidemics. [1]

\section{CONCEPT}

\subsection{The Project in the Context of the Millennium Development Goals}

The strategic goal of the project »Excellence Center for Development Cooperation - Sustainable Water Management in Developing Countries« is to contribute to the shaping of future subjects and scenarios through active cooperation with developing and industrialized countries. Such future subjects are closely linked with the Millennium Development Goals of the UN. The project focuses its activities on MDG \# 7 - »Ensure Environmental Sustainability «, and especially on the subtarget of embedding the principles of sustainable development into the politics of the respective countries and to reverse the loss of environmental resources. The realization of the other sub-targets in the field of »sustainability«, e.g., to halve the number of people without access to potable water until 2015 or to drastically improve the situation of slum dwellers until the year 2020 are critically dependent on the first one. By contributing to putting the topic of sustainable development on the political agenda of both industrialized and developing countries, and to establishing the administrative and societal framework necessary for implementation, the project activities guarantee a balance between short-term success, aimed at by politics and the economy, and assuring long-term development through a sustainable approach in the field of water (Figure 1).

\section{Objectives}

- Capacity building in DC and in GER on Sustainable Water Management

- Putting Sustainable Water Management on political agenda both in DC and in GER

- Cooperation at eye level with Developing Countries (DC) on Millennium Development Goals

\section{Strategies}

- Building a global network

- Establishing study programs

- Conducting joint research

- Providing suitable further education courses

- Creating a pool of experts

Implementation

- Establishing suitable structures for cooperation within the Exceed Network

- Developing an International Graduate Program Network on Sustainable Water Management (MSc and PhD)

- Developing dual MSc and PhD programs

- Conducting joint research

- Establishing a permanent guest chair and an international guest working group at TU Braunschweig

- Providing mobility opportunities for different target groups

- Providing opportunities for knowledge transfer

- Providing and distributing information, consultancy services, and networks

Figure 1: Concept of the Excellence Center for Development Cooperation at TU Braunschweig

\subsection{Capacity Building}

The main objective of the Exceed Project is »capacity building « in Developing Countries and in Germany through the training of and networking between experts. The project aims at conveying competencies and knowledge regarding the subject matter of sustainable water management to future experts and decision-makers, in order to qualify them to shape economic, organizational, and political change processes, thus ultimately attaining the MDG.

To achieve these goals, all participating institutions will implement study programs in the field of Sustainable Water Management on BSc, MSc, and PhD levels and provide state-of-the-art measures for further education of technical and scientific staff members of universities, enterprises, and authorities at the respective regions. The project contributes to strengthening the intercultural competences at TU Braunschweig as well as to the formation of an international science community, gaining an additional edge through the dialogue at eye level with Developing Countries. 


\subsection{Services and Expertise provided for Politics, Universities and Economy}

The Exceed Network guarantees that appropriate academic and structural expertise are made available to all relevant target groups (universities, research institutions, individual scientists and students, political decision makers, government agencies, enterprises, NGOs in Developing Countries, in Germany, and in other industrialized countries). All actors of development cooperation can benefit from the »think tank« thus generated.

The high-level expertise is generated through the dialogue at eye level of all partners within the network. Thus, an adequate and all-encompassing approach for the entirety of solutions and projects is developed, which ultimately leads to a lasting improvement of people's living conditions. The Center thus serves as a model for cooperation between universities and research institutions in Developing Countries with their counterparts in Germany and other industrialized countries.

\subsection{Structures of the Exceed Project}

The project approach is based upon the establishment of a world-wide network of partners active in the field of Sustainable Water Management. The coordinating unit (CU) is located at the TU Braunschweig. The three Satellite Centers (SC) are established in parallel in Jordan, Mexico, and Vietnam.

The Exceed Project for Sustainable Water Management works as the main link between the professional competencies regarding developing countries in those countries and those at TU Braunschweig and its partners in industrialized countries. It serves as a hub for the South-North, North-South, and South-South transfer.

The know-how and the competencies of the whole network are available for projects on problem solving and alike around the globe. Projects include, e.g., the development and implementation of study courses, needs analyses, measures for knowledge transfer, mutual advice, and the establishment of standards in developing countries.

The Exceed Project provides an organizational framework for development cooperation in the field of sustainable water management. All partners have outstanding expertise in the field and are parts of larger networks on all continents with development issues. The $\mathrm{CU}$ at TU Braunschweig guarantees the transfer of project results, procedures and structures between developing countries and from South to North and vice versa.

\subsection{Satellite Centers and Partners Abroad}

Three strategic partners in developing countries act as nuclei for the establishment of Satellite Centers (SC) in the regions relevant for sustainable water management. The SC (Figure 2) develop concepts and disseminate project results within their regional contexts. They are, thus, able to actively influence regional and nation-wide politics in water related issues. In order to do so, they use the joint expertise of all project partners and actively collaborate with stakeholders in their respective region. Through their networks and their academic reputation, they provide important contacts for research projects dealing with »water«. They also contribute actively to the establishment of study courses and the implementation of measures for knowledge transfer to enterprises and political stakeholders.

Following a joint needs analyses, all three SC have been selected based on the following criteria: (i) water situation in the country (per capita consumption), (ii) water supply, (iii) specific water problems, (iv) professional training opportunities, and (v) expertise of the partners in waterrelated issues. Special attention has been paid to the relevance of professional training opportunities in the respective countries.

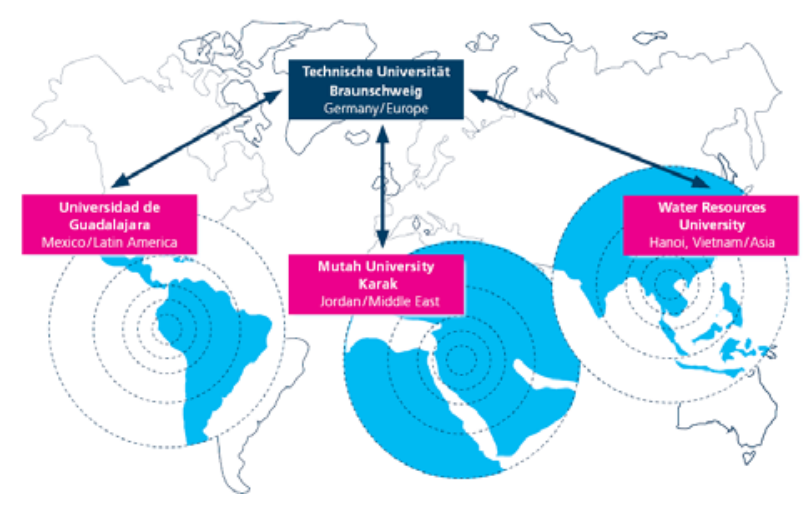

Figure 2: Exceed - The global Network on Sustainable Water Management in Developing Countries

\subsubsection{The Satellite Center in Jordan}

The Satellite Center at the Prince Faisal Dead Sea Research Center at Mutah University in Karak has the objective of developing approaches for water management in an arid country. Although Jordan is one of the most arid countries in the world, the per-capita use of water is higher than in Germany. By now, deserts make up 90\% of Jordan's surface. As the desertification grows worse, dwindling harvests, an irreversible degradation of the soil, and changes of the socio-economic structures go hand in hand. Against this backdrop, the processing and re-use of reclaimed wastewater in (semi-)arid regions imposes itself as a pivotal topic of the center. [11] For religious reasons, the use of wastewater constitutes a problem in Islamic countries. It is hence necessary to implement water projects into the socio-cultural structures and to launch an intercultural dialogue in order to ensure the success of the related projects.

The Center closely cooperates with the project partners in Jordan, Egypt, Syria, and Turkey in order to develop concepts to solve the problems of water scarcity, which 
had repeatedly led to political conflicts in this region in the past.

\subsubsection{The Satellite Center in Mexico}

The Universidad de Guadalajara in Guadalajara is one of the most important research institutions in Mexico in the field of hydro-metrology, sanitary and environmental engineering, and sustainable water management. The Satellite Center at the Universidad de Guadalajara, Centro Universitario de Ciencias Exactas y Ingenierías, aims at elaborating a concept for sustainable water management in mega-cities. Like Mexico-City, Guadalajara is growing incessantly, which leads to drastic social and environmental consequences.

The demand for water is straining the infrastructure and overtaxing supply capacities. The SC in Guadalajara intends to provide the scientific expertise for the solution of water management problems in mega-cities. [12] The activities in Mexico are supposed to set an example for regional politics and to be put into practice all over Latin America.

The Center closely cooperates with universities in Mexico, Brazil, and Argentine. The study programs offered are open to students from the smaller Hispano American countries, where MSc and PhD courses are not available.

\subsubsection{The Satellite Center in Vietnam}

The Water Resources University (WRU) in Hanoi was established in 1959 and has become the leading institution in Vietnam for the management and protection of water resources. The water situation in Vietnam is characterized through extreme water pollution, extreme flood waters, and extreme low waters.

The SC in Hanoi focuses on the subject matter of industrial wastewater, whose accumulation is increasingly becoming a problem in newly-industrializing developing countries. [13] The processing of wastewater bears fundamental significance in providing the Vietnamese population with clean potable water. In addition, the SC focuses on the flood and low flow management, and thus on the integrated resources management regarding water quantity and water quality. The Center aims at developing concepts for the treatment of industrial wastewater and the implementation of a water protection management system, thus making a significant contribution to reducing the number of infectious diseases and drastically cutting the infant mortality.

The Center closely collaborates with universities in Vietnam, Indonesia, P.R. China, and Thailand, since those countries are in need of an integrated water management system. In cooperation with the Asian Institute of Technology AIT in Bangkok postgraduate study programs will be offered for the entire South-East Asian region.

\subsubsection{Further Partners in Developing Countries}

The partner institutions in Developing Countries gain benefit from the expertise and competency of the Satellite Centers in their region, and from the access to a network of partners for joint research projects. All study programs offered by the Exceed Network are open for students from third-countries where corresponding educational opportunities do not exist. The concepts designed by the SC together with the regional partners can be transferred to other countries in the same region with similar environmental and socio-economic conditions.

\subsection{The Role of TU Braunschweig}

TU Braunschweig acts as the Coordinating Unit (CU) for the cooperation between the partners in developing and industrialized countries in the frame of the Exceed Project. Due to its scientific and research focus, the CU is integrated into Leichtweiss Institute for Hydraulic Engineering and Water Resources (LWI), and has access to the LWI's entire infrastructure. The Institutes of Environmental and Sustainable Chemistry, of Sanitary and Environmental Engineering, of Biotechnology, and of Geo-Ecology contribute to the project through their expertise and respective experiences in joint teaching, doctoral training, and research with developing countries.

A Scientific Coordinator takes care for close cooperation within the TU Braunschweig and support through the relevant departments and research groups as well as with the International Alumni and Career Service, the Technology Transfer Service, and the International Office. The CU is supported with administrative and social assistance for international researchers by the Alexander-von-Humboldt funded Mobile Researchers' Center at the TU Braunschweig.

\subsection{Connecting with Existing Networks}

\subsubsection{German Water Partnership}

The German Water Partnership GWP is a platform of coordinating agents in the field of water in Germany, which was founded in 2007 on the initiative of TU Braunschweig within the TU9. GWP today consists of 173 public and private partners in Germany, i.e. corporate enterprises, governmental and non-governmental organizations, scientific institutions, and expert associations in the area of water. They aim at bundling activities and initiatives of the German water industry, and at the world-wide provision of expertise. [14] TU Braunschweig contributes to GWP working groups and makes the results available to all Satellite Centers as well as to all partners in developing countries. This increases the expertise available at, and the range of activities and services offered by Exceed Network, which can then be employed in development cooperation in a much more purposeful and strategic way. The activities of the GWP 
are particularly linked to further education opportunities provided by the Exceed partners.

\subsection{2 »Knoten Weimar»}

The »Knoten Weimar « is an international transfer hub for environmental technologies. This initiative offers services in the fields of technology transfer as well as further education and training. The »Knoten Weimar« brings together the matching partners in transfer and educational projects, and arranges business contacts. [15] The Exceed Project cooperates with the »Knoten Weimar" in the implementation of educational activities and in development cooperation projects, while at the same time utilizing the »Knoten Weimar« to promote the project activities to a broader expert audience.

\subsubsection{German Alumni Water Network}

The German Alumni Water Network GAWN has been founded to better coordinate the activities of former students from German Universities and Development Cooperation Services in Germany. Through its database, it provides contact information online for alumni in the water sector, including information about further education opportunities, i.e. expert seminars or master programs. [16] TU Braunschweig co-authored GAWN and offers access to GAWN through its alumni networks. GAWN organizes summer schools and expert seminars on different continents.

\subsection{Management Structure}

TU Braunschweig act as contractor for the project and is legally responsible for the contract and management of the grant on behalf of the partnership. Its experts and academic teachers are involved in the administration, monitoring, and evaluation of all project-related educational and research activities.

The Satellite Centers coordinate the project activities in their respective regions. Each SC is responsible for the management and administration of its part of the project. Their experts and academic teachers are involved in all educational, research, and dissemination activities.

All partners participate in and are responsible for the monitoring, evaluation, assessment and development of the project activities. Each partner nominates a representative as member of the plenary meeting, among them the Management Board was elected. The Management Board assigns a Scientific Coordinator located at the TU Braunschweig as organizational core. The Scientific Coordinator ensures the communication among all partners and is responsible for the development and evaluation of the project. All partners jointly define and manage the network activities through a decision-making process based on regular contacts (either through meetings, e-mails, phone, or fax), the scientific coordinator being responsible for a fair contribution among the partners. The planning of the project, elaboration of the curricula, implementation of joint research activities, and realization of shared responsibilities are done through contacts between the Coordinating Unit, the Satellite Centers, and the other partners.

A kick-off meeting in 2009 was devoted to the basic coordination of the project. Later on, annual coordination meetings support the cooperation. These annual coordination meetings of the Management Board are primarily dedicated to general project management issues. The Management Board makes decisions on strategic planning of project activities, execution of the project dissemination activities, and planning and implementation of measures aiming at sustainability of the results after the end of the project.

An International Advisory Board gives advice to the Management Board on strategic issues and the general development of the project. Members of the International Advisory Board are international leading experts from the academia and industry worldwide.

Figure 3 shows the entire management structure of the Exceed Project.

\section{CONCLUSION OR WHY WE DO THAT?}

Global problems do not stop at national borders. The worldwide migration is often caused by lacking prosperity at home. As a consequence of climate change we in Germany will be confronted soon with similar problems as in Developing Countries. A global networking and knowledge transfer only might help to find suitable solutions for the global problems.

TU Braunschweig stands on 3 pillars: Education Research - Internationality. [17] Our partners are mostly our alumni; that creates a reciprocal trust. TU Braunschweig is particularly recognized in environmental and water research. TU Braunschweig as member of the TU9, the nine leading Institutes of Technology in Germany, initiated the foundation of the German Water Partnership GWP. The TU9 aims at giving scientific support to the global oriented water industry.

The City of Braunschweig has a long-term experience with the recycling of wastewater and for the utilization of reclaimed wastewater in the agriculture that could serve as a model for the solution of global water problems. [18]

The Exceed Partners are aiming at extending their cooperation also to the Sub-Sahara Region. Universities and Research Institutions in this region are invited to join our Global Network for Sustainable Water Management in Developing Countries.

Further information is available under: http://www.exceed.tu-braunschweig.de. [19]

\section{ACKNOWLEDGEMENTS}

The financial support of this Exceed Project for 20092014 through the Federal Ministry for Economic Cooperation and Development (BMZ) and the German Academic Exchange Service (DAAD) is gratefully acknowledged. 


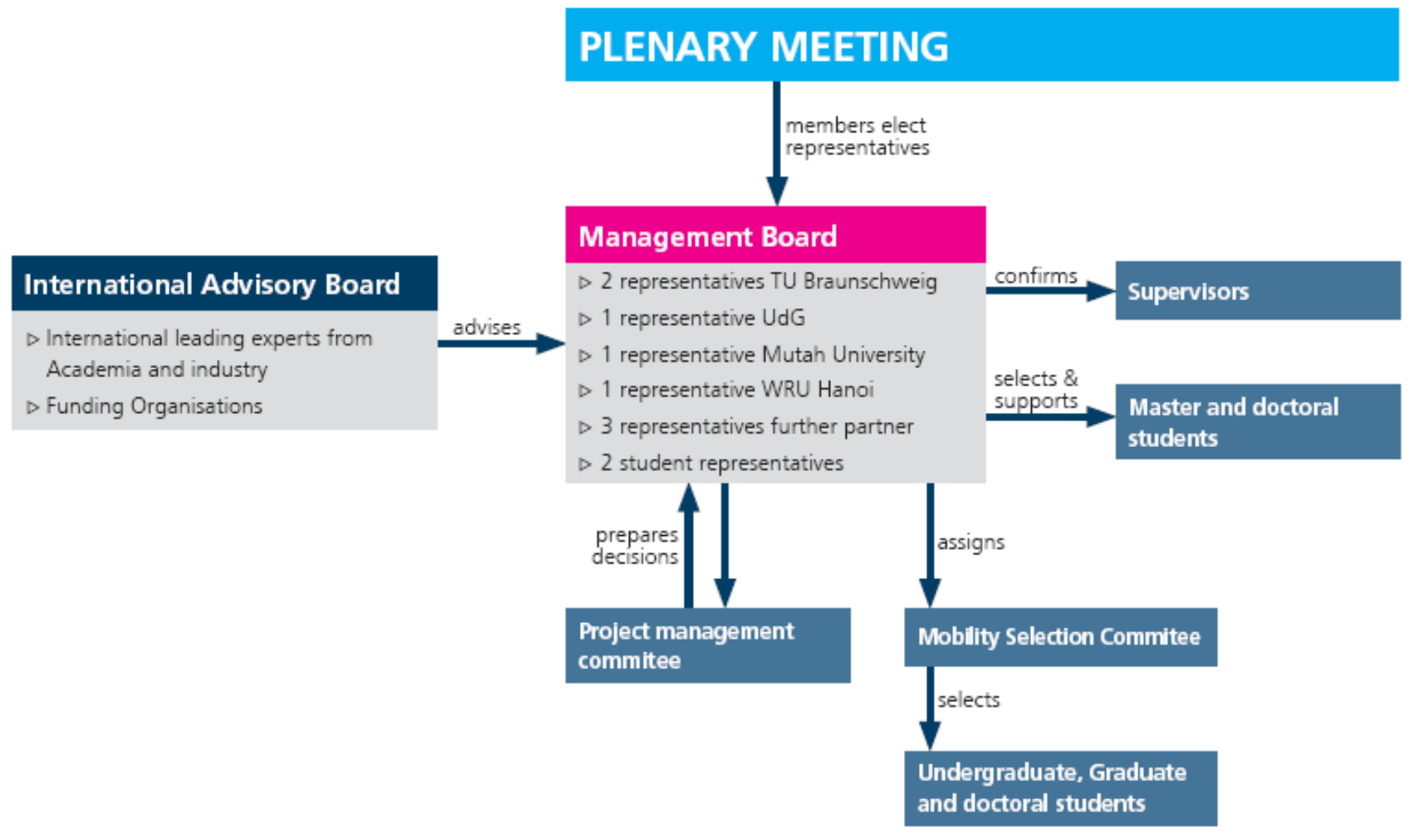

Figure 3: The Management Structure of the Exceed Project

\section{REFERENCES}

[1] http://www.un.org/millenniumgoals/;

http://www.who.int/water_sanitation_health/mdg1/e n/index.html;

UNESCO: Water in a changing world, The United

Nations World Water Development Report 3, Paris 2009, ISBN: 978-9-23104-095-5

[2] http://www.lwi.tu-bs.de/en_index.html

[3] Elshemy, M.; Le, T.T. H.; Meon, G.; Heikal, M. T.: Water quality modeling for the southern part of Aswan High dam reservoir, Lake Nubia. Proceed. "First European IAHR Congress". May 4-6, 2010, Edinburgh, UK.

[4] M.E. Aydin, H. Wichmann, M. Bahadir: Priority organic pollutants in fresh and wastewater of Konya Turkey. Fresenius Envir. Bull. 13, 118-123 (2004)

[5] J. Recio, H. Oumeraci: Process-based stability formulae for coastal structures made of GSC. Coastal Engineering 6, 260-284 (2009)

[6] F. Koelsch, K. Fricke, W. Mueller: Carbon Trade Project: Biological Waste Treatment for Gaobeidian, China. Clean Soil, Air, Water 35, 504-507 (2007)

[7] http://www.daad.de/entwicklung/exceed/

[8] KfW: Granting Development, Evaluating Results. 8th Evaluation Report on Projects and Programs in Developing Countries, Frankfurt 2004 (in German) http://www.kfw-entwicklungsbank.de/DE_Home/ Evaluierung/Ergebnisse und Veroeffentlichungen/ Ex_Post-Evaluierungsberichte/PDF-Dokumente
[9] Distance learning master course PROWATER http://www.lwi.tu-bs.de/prowater/index.htm

[10] G. Meon, F. Yin: Reduction of eutrophication of lakes: modelling tools and experiments - example Lake Chao, China. Proc. IFAT, Shanghai (2008)

[11] F. Al Nasir, M. Batarseh: Agricultural reuse of reclaimed water and uptake of organic compounds: Pilot study at Mutah University WWTP, Jordan. Chemosphere 72, 1203-1214 (2008)

[12] O. Bernard, V. Gonzales Alvarez et al.: An integrated system to remote monitor and control anaerobic wastewater plants through the internet. Water Sci. Technol. 52, 457-464 (2005)

[13] http://www.wru.edu.vn

[14] http://www.germanwaterpartnership.de

[15] http://www.bionet.net/index.php?id=42

[16] http://www.gawn.de/

[17] http://www.tu-braunschweig.de/

[18] http://www.stadtentwaesserungbraunschweig.de/wasserrecycling.html

[19] http://www.exceed.tu-braunschweig.de 